\title{
Ocean wanderers
}

\author{
The ocean is a difficult environment to study due to its vast, remote regions. Climate change is impacting \\ on marine biology and we need to better understand how this will manifest.
}

The ocean is full of life, but most of it is too small for the human eye to see. The microscopic plants of the ocean, made up of many species but known collectively as phytoplankton, produce half of Earth's oxygen through their photosynthetic growth. Phytoplankton are at the base of the ocean food chain and form a critical part of the global carbon cycle by driving the biological carbon pump - transferring carbon from the atmosphere to the deep ocean. Whilst we cannot see individual plankton, when conditions are right they grow at an amazing rate, resulting in a bloom of such high density that it can be seen from space. Their growth relies on the right temperature, sufficient nutrients and minerals (such as iron), and light - meaning they are limited to the upper ocean and the maximum depth to which light can penetrate. Small changes in these properties can disproportionately impact on individual species. But these are not the only changes that can affect the growth and survival of phytoplankton.

Anthropogenic greenhouse-gas emissions are increasing and so is the amount of carbon and heat entering the ocean. The result is warming of surface waters and a lower $\mathrm{pH}$, that is, a more acidic environment. It is not just carbon that needs to be considered when talking about emissions. Other compounds should be considered, such as higher emissions of reactive nitrogen (that is, nitrogen compounds that are available for plant growth) from northeastern Asia due to surging population and development. The deposition of this additional nitrogen into the North Pacific Ocean, where photosynthesis is limited by low nitrogen, has the potential to shift it to being a phosphate-limited region (I. Kim et al., Science 346, 1102-1106; 2014).

These changes may not appear to have broader impacts but consider the importance of phytoplankton in that transfer, and subsequent storage, of carbon. As warming increases stratification, regions of the ocean may have less mixing of nutrient-rich waters into the water where phytoplankton grow. This could result in a higher carbon to nutrient ratio, causing greater carbon storage and a stronger carbon pump (T. DeVries \& C. Deutsch, Nature Geosci. 7, 890-894; 2014), but it is dependent on the carbon being exported to depth.

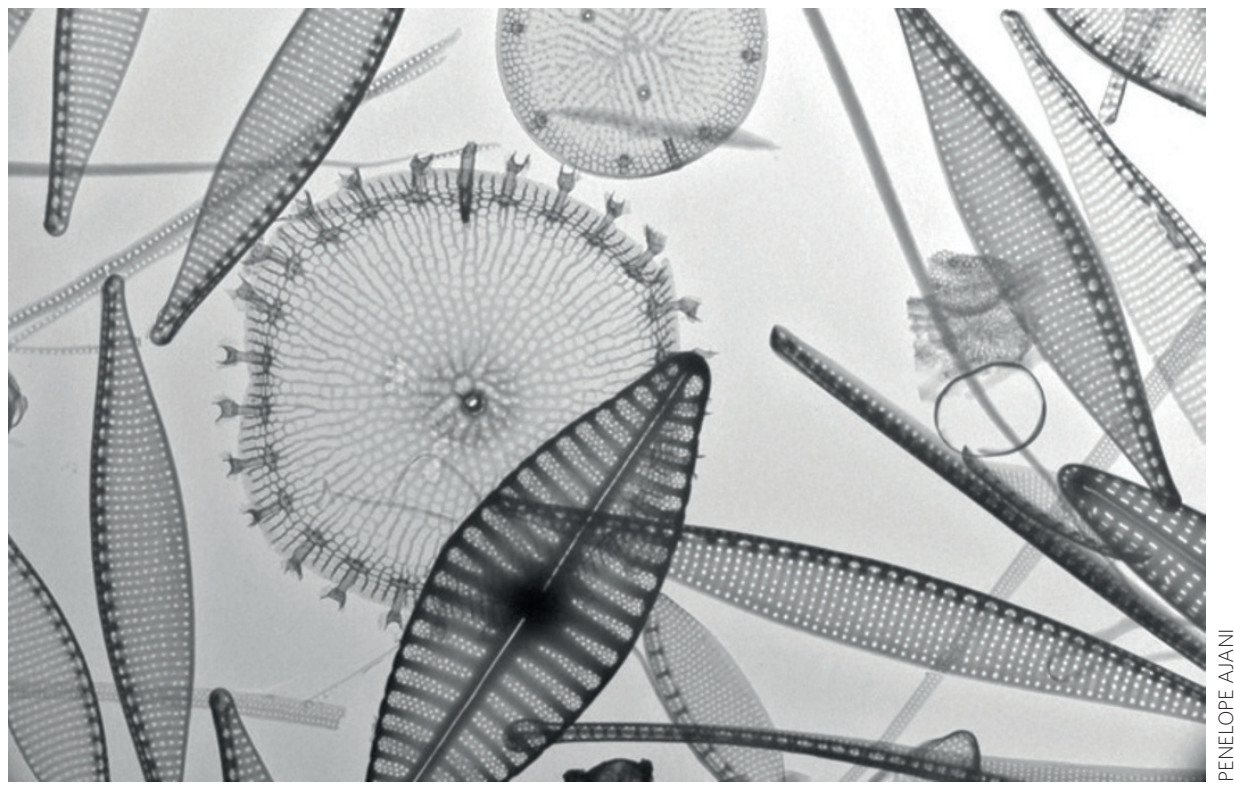

In a web focus this month, Pressures on phytoplankton (http://www.nature.com/ nclimate/focus/phytoplankton/index.html), we present a collection of opinion and research pieces that have been published in this issue and selected from our archive. These investigate the many ways that climate change is impacting on marine phytoplankton.

Studies have historically been undertaken in the laboratory, investigating the impact of a single environmental variable, such as ocean acidification, on one or a small number of species. However, environmental changes are not happening in isolation - changes may compound (or conversely, counter) each other creating unknown impacts. Combining this with individual species responses and the resulting interaction between species presents a challenge that researchers need to find new ways to address. This is discussed in a Commentary in this issue (page 12) outlining the lessons to be learnt from the fast-growing field of ocean acidification and the need to set priorities to advance our understanding of the changes in the ocean.

The ability to model and predict impacts relies on improving our knowledge and having the right data available. Boyd et al. (page 71) set out a 'roadmap' (see the News \& Views by Dunne for more information, page 20) to combine an ecosystem model with field observations to investigate multiple stressors and their impacts on classes of phytoplankton at a regional scale. Application of this sort of analysis will help guide laboratory and field studies to expand future research.

This all relies on strong support for ocean observation, technology development and international collaboration, as discussed in a Commentary on page 4 . Our knowledge of the physical properties of the ocean has been greatly enhanced by the Argo programme, which includes 3,600 robots sampling the upper $2,000 \mathrm{~m}$ of the ocean. This programme is being expanded, with tests underway on oxygen and biological sensors, and is a great example of observation, development and collaboration. The recent Qingdao Global Ocean Summit brought together leading oceanographic research institutes and universities to discuss how to promote collaboration and networks.

Developing our understanding of marine systems is key to ensuring a healthy ocean and planet in the years ahead.

Corrected online: 16 April 2015 


\section{Correction}

In the Editorial 'Ocean wanderers'

(Nature Clim. Change 5, 1; 2015) the image did

not show marine phytoplankton. Corrected

after print 16 April 2015. 